\title{
Transduction of yeast cytosine deaminase mediated by HIV-1 Tat basic domain into tumor cells induces chemosensitivity to 5 -fluorocytosine
}

\author{
Hakjoo Lee ${ }^{1}$, Jiyoon Ryu ${ }^{1}$, Kyung-Ae $\mathrm{Kim}^{1}$ \\ Kil Soo Lee ${ }^{1}$, Jae Young Lee ${ }^{2}$ \\ Jae-Bong Park ${ }^{2}$, Jinseu Park ${ }^{1,3}$ \\ and Soo Young Choi $\mathrm{i}^{1,3}$ \\ ${ }^{1}$ Division of Life Sciences \\ College of Natural Sciences and \\ ${ }^{2}$ Dept. of Biochemistry \\ College of Medicine, Hallym University \\ Chuncheon 200-702, Korea \\ ${ }^{3}$ Coressponding author: Tel, 82-33-248-2112; \\ Fax, 82-33-241-1463; E-mail, sychoi@hallym.ac.kr, \\ jinpark@hallym.ac.kr
}

Accepted 22 December 2003

Abbreviation: $y C D$, yeast cytosine deaminase; 5-FC, 5-fluorocytosine; 5-FU, 5-fluorouracil

\begin{abstract}
Enzyme/prodrug approach is one of the actively developing areas for cancer therapy. In an effort to develop more effective enzyme/prodrug systems, cell-permeable cytosine deaminase was produced by fusing yeast cytosine deaminase (yCD) in frame with RKKRRQRRR domain of HIV-1 Tat which is an efficient delivery peptide of the foreign proteins into cells. The purified Tat-yCD fusion protein expressed in Escherichia coli was readily transduced into mammalian cells in a time- and dose-dependent manner. A significant level of the transduced Tat-yCD protein was recovered in the cell and was stable for $24 \mathrm{~h}$ as indicated by both results of the enzymatic assay of 5 -fluorocytosine (5-FC) conversion to 5-fluorouracil (5-FU) and Western blot analysis. The cells transduced with Tat-yCD become highly sensitive to the cytotoxicity of 5-FC, while cells treated with yCD are unaffected by $5-F C$. In addition, a strong bystander effect was observed with conditioned media from cells transduced with Tat-yCD added to non-transduced cells. Tat-yCD fusion protein demonstrated here for its ability to transduce into cells and convert nontoxic prodrug $5-\mathrm{FC}$ to the toxic antimeta-
\end{abstract}

bolite 5-FU, may be a useful approach for cancer therapy.

Keywords: cancer; cytosine deaminase; prodrug; transduction; Tat

\section{Introduction}

Enzyme/prodrug therapy is being developed as treatment for cancer and other pathological conditions. Cytosine deaminase/5-fluorocytosine $(5-\mathrm{FC})$ strategy is one of most widely tested enzyme/prodrug strategies, either in animal models or clinical trials (Connors, 1995; Greco and Dachs, 2001). Cytosine deaminase (CD) (EC 3.5.4.1) is an enzyme found in many bacteria and fungi, but not in mammalian cells that do not ordinarily metabolize cytosine to uracil. $C D$ has the ability to deaminate the nontoxic prodrug 5-fluorocytosine $(5-F C)$ into the highly toxic compound 5fluorouracil (5-FU) which eventually inhibits DNA synthesis leading to cell death (Mullen et al., 1992).

Both bacterial and yeast CDs have been exploited in $\mathrm{CD} / 5-\mathrm{FC}$ enzyme prodrug gene therapy. Although bacterial $C D$ in gene-directed $C D / 5-F C$ therapy has been tested in various tumor models, the limited therapeutic effects of bacterial CD were obtained, possibly due to the low conversion efficiency of 5-FC to 5-FU (Kievit et al., 1999). Recently, CD derived from yeast has been exploited in enzyme/prodrug strategy, based on its conversion efficieny of $5-\mathrm{FC}$ to $5-F U$. Previous studies demonstrated that yeast CD is superior at deaminating $5-\mathrm{FC}$ into 5 -FU comparing to that of bacterial $C D$, thus improving the efficacy of the CD/5-FC treatment strategy (Hamstra et al., 1999; Kievit et al., 1999). In addition, the enhanced conversion efficiency for 5-FC by yeast CD increased the bystander effect as well as the efficacy of radiotherapy (Kievit et al., 2000). These data suggested that the use of $y C D$ increase the therapeutic potential of the $C D / 5-F C$ treatment strategy.

Current $\mathrm{CD} / 5-\mathrm{FC}$ enzyme prodrug therapy has been focused on the development of gene therapy utilizing bacterial or yeast CD gene. Because of some constraints, including gene delivery, prolonged gene expression in cancer gene therapy, the potential of protein therapy could be considered (Verma and Somia, 1997). However, one of the major limitations 
of protein therapy is the difficulty of efficient intracellular delivery of target proteins. CD enzyme was modified to obtain targeting specificity by conjugation with antibodies that were able to direct enzyme to the tumor cell surfaces (Senter et al., 1991; Wallace et al., 1994; Deckert et al., 2003). These modifications have been shown to increase antitumor activities in combination with prodrug 5-FC partly due to increase in intratumoral drug concentrations. In vivo delivery of $C D$ enzyme has been tried by exploiting implanted capsules containing bacterial or yeast CD (Katsuragi et al., 1987). Significant reduction of the tumor growth and cytotoxic changes were observed in the implanted experimental animals. These results suggest that $C D$ enzyme can be used to remove tumors by regional delivery. Therefore, efficient cellular delivery of $C D$ enzyme may result in enhanced therapeutic efficacy in treatment of cancers.

Previous studies have shown that the entire HIV-1 Tat protein or parts of it can deliver foreign functional proteins into cells, when added extracellularly. A basic sequence (RKKRRQRRR) from the HIV-1 Tat protein has been reported to be responsible for intracellular delivery of proteins (Watson and Edwards, 1999; reviewed in Schwarze et al., 2000). This basic domain from HIV-1 Tat has been shown to have an ability to deliver several proteins of sizes up to $120 \mathrm{kDa}$ into cells, both in vitro and in vivo (Fawell et al., 1994; Nagahara et al., 1998; Schwartze et al., 1999; VoceroAkbani et al., 1999). We also have reported that the genetic in-frame Tat-green fluorescent fusion protein (Tat-GFP), human Tat-catalase and human Tat-Cu, $\mathrm{Zn}$ superoxide dismutase (Tat-SOD) were efficiently transduced into HeLa cells (Kwon et al., 2000; Jin et al., 2001; Park et al., 2002).

For potential use of cell-permeable cytosine deaminase in the chemotherapy of cancer by a combination of $C D$ enzyme and 5-FC, recombinant cytosine deaminase fusion protein, Tat-yCD, was obtained by expressing yeast CD in frame with HIV-1 Tat basic domain. The transduction profile of Tat-yCD into mammalian cells was then determined by Western blot analysis and enzymatic activity assay. The cells treated with Tat-yCD exhibited a dose- and timedependent increase in their intracellular level of the protein as well as enzymatic activity. It was found that the prodrug 5-FC had significant cytotoxic effects on tumor cells transduced with Tat-yCD in vitro, but not with $y C D$ lacking Tat basic domain. The bystander effect was also observed when nontransduced cells were cultured with supernatant from cells transduced with Tat-yCD in the presence of $5-\mathrm{FC}$.

\section{Materials and Methods}

\section{Vector construction}

The pTat-yCD expression vector was constructed to express the basic domain (amino acids 49-57) of HIV-1 Tat as a fusion with yCD as followings. Complete yeast cytosine deaminase gene (FCY1, 477 bp) sequence was amplified from a Saccharomyce cerevisiae genomic DNA as template using polymerase chain reaction (PCR) by Pfu DNA polymerase (Clontech). The sense primer was: 5'-CTCGAGGTGACAGGGGGAATGGCAAGC-3' and antisense primer: 5'CTCGAGCTACTCACCAATATCTTC-3'. The PCR product was digested with $\mathrm{XhOl}$ and subcloned into $\mathrm{Xhol}$ site of pHisTat (Jin et al., 2001). We also constructed pET-yCD expression vector which expresses the $y C D$ fusion protein without the basic domain of HIV-1 Tat by inserting the same PCR product digested with Xhol into Xhol-digested pET15-b (Invitrogen, Carlsbad, CA). Clones with the expected insert were selected using Xhol restriction analysis and then analyzed by sequencing (Sambrook et al., 1989).

\section{Expression and purification of recombinant fusion enzymes}

BL21 E. coli (Pharmacia) transformed with plasmids encoding the $y C D$ or Tat-yCD fusion proteins were grown overnight at $37^{\circ} \mathrm{C}$ in $\mathrm{LB}$ broth supplemented with $100 \mathrm{mg} / \mathrm{ml}$ ampicillin (Park, 2001). The overnight culture was diluted ten-fold with fresh LB media and cultured at $37^{\circ} \mathrm{C}$ with shaking at $250 \mathrm{rpm}$ until $0 . D_{600}$ $=1.0$. Protein expression was induced by addition of IPTG to a final concentration of $0.5 \mathrm{mM}$ for $4 \mathrm{~h}$. To prepare the denatured Tat-yCD fusion proteins, the induced cells were harvested and lysed by sonication in binding buffer $(5 \mathrm{mM}$ imidazole, $500 \mathrm{mM} \mathrm{NaCl}, 20$ $\mathrm{mM}$ Tris- $\mathrm{HCl}, \mathrm{pH}$ 7.9) containing $6 \mathrm{M}$ urea. After removal of cell debris by centrifugation, the clarified cell extract was then loaded onto the $\mathrm{Ni}^{++}$-IDA column. The column was washed first with binding buffer without $6 \mathrm{M}$ urea and then with wash buffer (80 mM imidazole, $0.5 \mathrm{M} \mathrm{NaCl}$, and $20 \mathrm{mM}$ Tris $-\mathrm{HCl}$, $\mathrm{pH}$ 7.9). Proteins were eluted by elute buffer (1 M imidazole, $0.5 \mathrm{M} \mathrm{NaCl}$ and $20 \mathrm{mM}$ Tris- $\mathrm{HCl} \mathrm{pH} \mathrm{7.9),}$ followed by desalting with a PD10 column (Amersham). The native Tat-yCD fusion protein was obtained by the same procedure mentioned above without denaturing agent. The protein concentration was determined with Bradford protein assay (Biorad) using bovine serum albumin as a standard (Bradford, 1976). The purified $y C D$ fusion proteins dissolved in PBS containing $20 \%$ glycerol were aliquoted and stored at $-80^{\circ} \mathrm{C}$. 


\section{Cell culture and transduction of fusion proteins}

HeLa cells used in these studies were grown in Dulbecco's Modified Eagle's Medium (DMEM) containing $20 \mathrm{mM}$ HEPES/NaOH $(\mathrm{pH} 7.4), \quad 5 \mathrm{mM}$ $\mathrm{NaHCO}_{3}, 10 \%$ fetal bovine serum (FBS) and antibiotics $(100 \mathrm{mg} / \mathrm{ml}$ streptomycin, $100 \mathrm{U} / \mathrm{ml}$ penicillin) at $37^{\circ} \mathrm{C}$. For the transduction of $y C D$ fusion proteins, HeLa cells were grown to confluence in 6-well plate. Then, HeLa cells were treated with various concentrations of $y C D$ fusion proteins for indicated time intervals. Then, the cells were washed with phosphate buffered saline (PBS) and trypsinized for $10 \mathrm{~min}$ (Gibco BRL). Cell lysates were prepared by incubating with lysis buffer $(150 \mathrm{nM} \mathrm{NaCl}, 0.02 \%$ sodium azide, $100 \mathrm{mg} / \mathrm{ml} \mathrm{PMSF,} 1 \%$ triton X-100, $50 \mathrm{nM}$ Tris$\mathrm{HCl}, \mathrm{pH}$ 8.0.) at $4^{\circ} \mathrm{C}$ for $30 \mathrm{~min}$ to perform Western blot analysis and enzyme assay.

\section{Western blot analysis}

Fifty $\mathrm{mg}$ of proteins from each whole cell lysate were run on to an SDS-12\% polyacrylamide gel. Proteins were electrotransferred to a nitrocellulose membrane, which was then blocked with $10 \%$ dry milk in PBS. For detection of $y C D$ fusion proteins, the membrane was probed with rabbit anti-tagged histidine polyclonal antibody (Clontech, dilution 1:2,000), followed by incubation with horseradish peroxidase-conjugated goat anti-rabbit antibody (Sigma, dilution 1:10,000). The bound antibodies were visualized by enhanced chemiluminescence according to the manufacturer's instruction (ECL; Amersham) (Kwon et al., 2000; Eum et al., 2003). For detection of cellular proteins, primary antibodies against PARP (mouse monoclonal antibody, Biomol), Bcl-2 (mouse monoclonal antibody, Santa Cruz), p53 (mouse monoclonal antibody, Neomarker), p21 (mouse monoclonal antibody, Pharmingen) and actin (mouse monoclonal antibody, Oncogene research products) were used (Draus et al., 2001).

\section{Determination of $y C D$ activity}

The deamination activity of purified $y C D$ fusion protein or transduced $y C D$ in cell extracts was measured by monitoring conversion of 5-FC to 5-FU (Kuriyama et al., 1999). To determine the activity of transduced enzyme, $100 \mathrm{ml}$ of cell lysate was added to $200 \mathrm{ml}$ of PBS containing 5-FC (30 mM, Sigma Co.) and incubated for $24 \mathrm{~h}$ at $37^{\circ} \mathrm{C}$. Then $50 \mathrm{ml}$ of this solution was quenched with $1 \mathrm{ml}$ of $0.1 \mathrm{~N} \mathrm{HCl}$. The millimolar concentrations of 5-FC and 5-FU were measured by an UV spectrophotometer (Uvikon 930, Kontron, Ins.) at $290 \mathrm{~nm}$ and $255 \mathrm{~nm}$ :

$5-\mathrm{FC}[\mathrm{mmol} / \mathrm{l}]=0.119 \times \mathrm{A}_{290}-0.025 \times \mathrm{A}_{255}$ $5-\mathrm{FU}[\mathrm{mmol} / \mathrm{l}]=0.185 \times \mathrm{A}_{255}-0.049 \times \mathrm{A}_{290}$

\section{Cytotoxic assay}

The cytotoxic activity of transduced $y C D$ was assessed by measuring cell viability of $\mathrm{HeLa}$ cells in the presence or absence of $5-\mathrm{FC}$. The cells were plated at the density of $1 \times 10^{4}$ cells per well in 24 well plates. The following day the media were removed and fresh complete media were added. The cells were treated with fusion proteins for $2 \mathrm{~h}$ and washed with PBS. The transduced cells were incubated in the complete media containing 5-FC for $24 \mathrm{~h}$. These procedures were repeated every $24 \mathrm{~h}$. Cell viability was estimated after $96 \mathrm{~h}$ by colorimetric assay using MTT (3-(4,5-dimethylthiazol-2-yl)-2,5-diphenyltetrazolium bromide) (Sigma Co.) (Song and Boyce, 2001).

\section{Analysis of the bystander effect}

HeLa cells were plated at $6 \times 10^{5}$ cells/well in six-well plates. When they were $70 \%$ confluent, cells were treated with $y C D$ fusion proteins $(0.01-50 \mathrm{mg} / \mathrm{ml})$ for $2 \mathrm{~h}$ and washed with PBS to remove non-transduced $y C D$. The transduced cells were then incubated for $24 \mathrm{~h}$ in the presence of 5-FC $(0.01-50 \mathrm{mM})$. To analyze the bystander effect, $0.5 \mathrm{ml}$ of conditioned media from the transduced cells was collected and transferred to non-transduced cells every $24 \mathrm{~h}$ for 4 days and viable cells were determined by the MTT assay.

\section{Results}

\section{Expression and purification of Tat-yCD fusion protein expression vectors}

To develop an expression system for over-expression and ready purification of the cell permeable yeast cytosine deaminase ( $y C D$ ) protein, pTat-yCD expression vector containing consecutive DNA sequences encoding yeast CD, HIV-1 Tat basic domain (Tat49$57)$ and six consecutive histidine residues at the amino-terminus was constructed (Figure 1A) and also constructed was a pET-yCD expression vector to produce control yCD protein without HIV-1 Tat basic domain (Figure 1A).

Following the induction of expression, the cell lysates containing either Tat-yCD or yCD were prepared under denaturing conditions or native conditions. The $y C D$ fusion proteins containing six histidine residues at the $\mathrm{N}$ terminus were purified by metal chelate chromatography. The purification results of the chromatographic fractions are shown in Figure 1B. An analysis of the purified Tat-yCD protein by SDSPAGE showed that Tat-yCD migrated at a higher apparent molecular mass than control yCD protein, which lacked the Tat sequence, due to the presence of the Tat basic domain. The protein was found to be nearly homogeneous and $>80 \%$ pure, as deter- 
mined by an SDS-PAGE analysis with Coomassie Brilliant blue staining (Figure $1 \mathrm{~B}$ ). The purified products were further confirmed by Western blot analysis using a rabbit polyclonal antibody to histidine (Figure 1C). Tat-yCD and $y C D$ fusion proteins were detected at the corresponding bands, respectively.

To determine whether recombinant fusion proteins expressed in $E$. coli were enzymatically active and able to sensitize to prodrug, the ability of $y C D$ and Tat-yCD purified in a native form to deaminate 5-FC were analyzed. Enzymatic activity of purified $y C D$ and

A

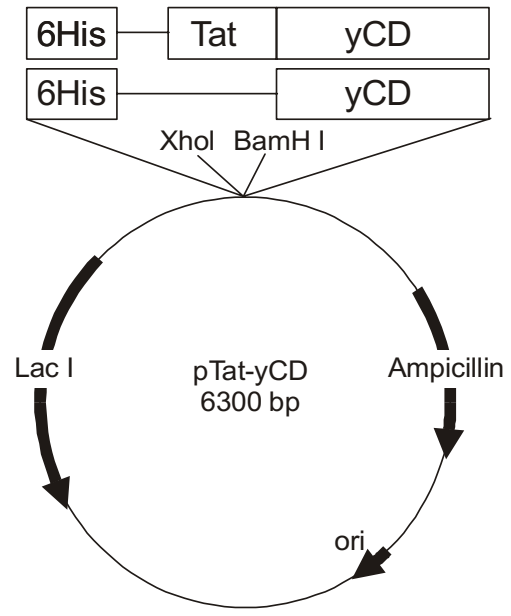

B

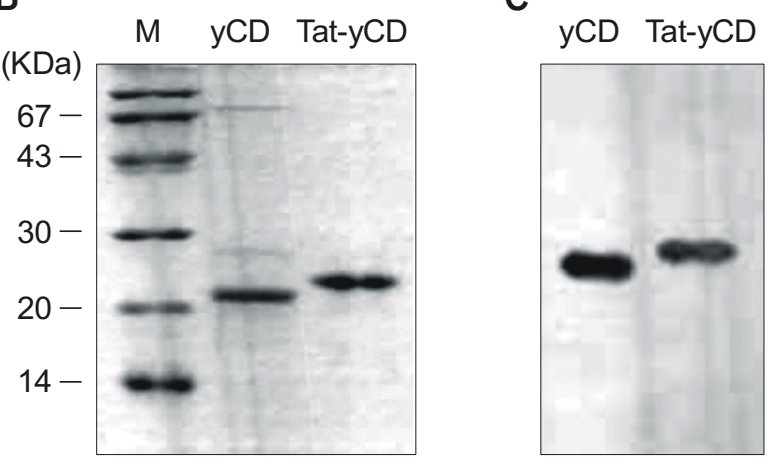

Figure 1. Expression and purification of Tat-yCD and $y C D$ fusion proteins. (A) Schematic representation of Tat-yCD and $y C D$ expression vectors. Tat-yCD and $y C D$ expression vectors were constructed by inserting the coding sequence for yeast cytosine deaminase into pHisTat (Jin et al., 2001) and pET-15b, respectively. (B) Analysis of purified $y C D$ and Tat-yCD fusion proteins. $y C D$ fusion proteins purified by affinity chromatography on a nickel column were separated by $12 \%$ SDS-PAGE and stained with Coomassie Brilliant blue. Lane M, molecular mass marker. (C) Western blot analysis of purified $y C D$ fusion proteins. The purified fusion proteins were separated by $12 \%$ SDSPAGE and then transferred to nitrocellulose membranes. The membranes were incubated with a rabbit anti-histidine antibody as the first antibody and then anti rabbit $\lg G$ as the secondary antibody. The blot was developed by the ECL method.
Tat-yCD was measured by conversion of 5-FC to 5-FU. In an enzyme assay, either purified yCD or Tat-yCD in native form converted 5-FC to 5-FU at a similar efficiency (data not shown). However, purified fusion proteins denatured with $6 \mathrm{M}$ of urea did not show any detectable levels of $y C D$ activity (data not shown). These results indicate that the expressed and refolded $y C D$ and Tat-yCD fusion proteins in $E$. coli had been renatured into native structural conformation and were possessed of enzyme activity as native CD, respectively.

A

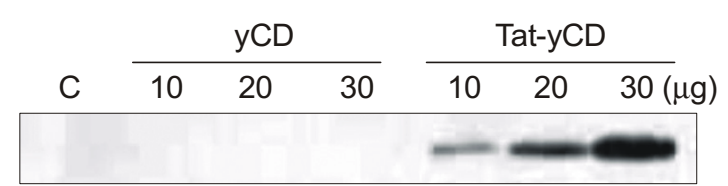

B

$\begin{array}{lllllll}\text { C } & 15 & 30 & 60 & 90 & 120 & 180(\min )\end{array}$

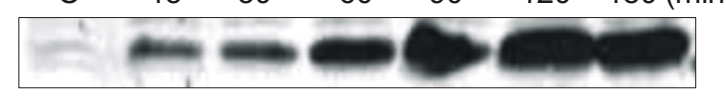

C
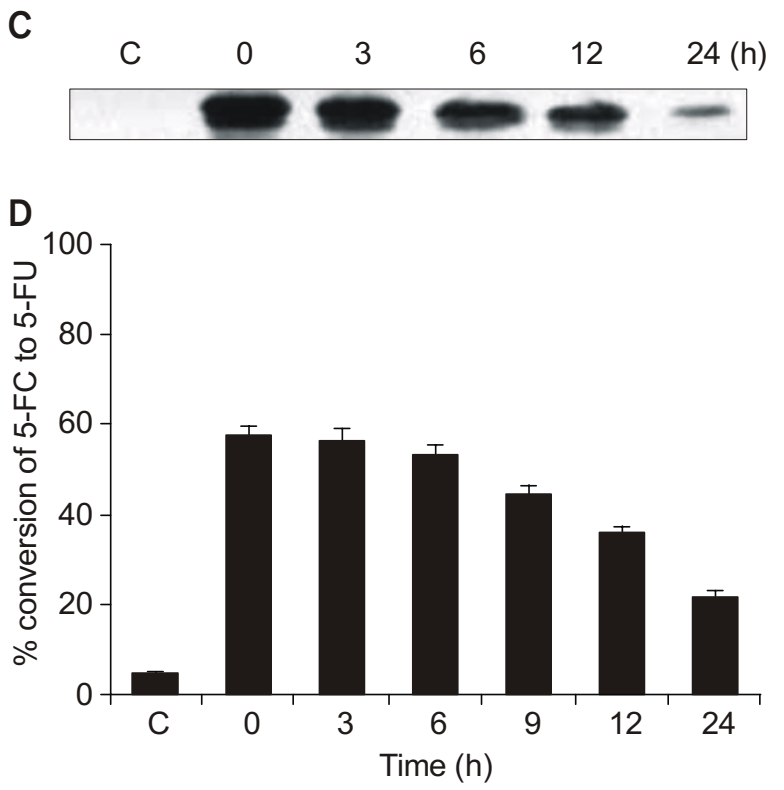

Figure 2. Transduction kinetics of Tat-yCD fusion protein. (A) Dosedependent transduction of $y C D$ fusion proteins into cultured HeLa cells. HeLa cells were treated with various concentrations of Tat-yCD or yCD for $2 \mathrm{~h}$. Cellular lysates were prepared for Western blot analysis for determining the levels of transduced protein. (B) Timedependent transduction of Tat-yCD into HeLa cells. The cells were transduced with $30 \mathrm{mg}$ of the Tat-yCD for indicated time. To examine stability of transduced Tat-yCD, the cells were incubated with $30 \mathrm{mg}$ of the Tat-yCD for $2 \mathrm{~h}$ and washed twice with serum-free media. The cells were incubated with new culture media and harvested at indicated time. Cell lysates were analyzed by Western blotting $(C)$ and by measuring the enzyme activity (D), as described in "Materials and Methods". C, non-transduced cell lysates. 


\section{Transduction profiles of yCD fusion proteins into mammalian cells}

To test the efficiency of Tat-fusion for intracellular transfer, the kinetics of the denatured Tat-yCD fusion proteins transduction into cells was carried out. The denatured $y C D$ fusion proteins were added to culture media of HeLa cells at various concentrations for 2 $\mathrm{h}$ and the resulting transduced protein levels were analyzed by Western blotting. As shown in Figure 2A, the level of the transduced proteins in the cells treated with denatured Tat-yCD increased concomitantly with the amount of protein treated into the cells. In contrast, the $y C D$ lacking the Tat basic domain was not transduced into the cells under the same experimental conditions. Thereafter, the denatured Tat-yCD proteins were added to culture media of HeLa cells at a concentration of $30 \mathrm{mg}$ per $\mathrm{ml}$ for various time periods and the resulting levels of transduced proteins were analyzed by Western blotting. As shown in Figure 2B, the intracellular level of transduced Tat-yCD into the cultured cells was initially detected after $5 \mathrm{~min}$, peaked after $2 \mathrm{~h}$, and then remained same over a further $1 \mathrm{~h}$ of observation. This dose- and time-dependent manner of transduction indicates that Tat-yCD was efficiently transduced into the cells. The intracellular stability of tranceduced TatyCD into HeLa cells were shown in Figure $2 \mathrm{C}$. The apparent degradation of transduced Tat-yCD was observed as a function of incubation time. However, significant levels of transduced protein were persisted in HeLa cells during $24 \mathrm{~h}$. In addition, significant levels of enzyme activity were maintained in the HeLa cells transduced with Tat-yCD for $24 \mathrm{~h}$, indicating the stability of the transduced Tat-yCD in cells (Figure 2D). These results demonstrate that transduced TatyCD into cells is biologically active and able to convert the nontoxic prodrug $5-\mathrm{FC}$ to the toxic metabolite 5-fluorouracil.

\section{Cytotoxicity of transduced Tat-yCD fusion protein in the presence of 5-FC}

To determine whether transduced Tat-yCD can exert its cytotoxic effect on the tumor cells, we evaluated the viability of the cells transduced with Tat-yCD in the presence or absence of prodrug $5-\mathrm{FC}$. In the

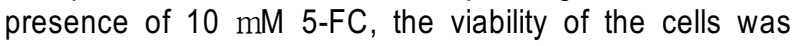
significantly decreased by treatment of Tat-yCD in a dose-dependent manner, while control yCD was not toxic to the target cells (Figure $3 \mathrm{~A}$ ). The cell viability of HeLa cells treated with $5 \mathrm{mg}$ of Tat-yCD and 10 mM 5-FC was decreased by approximately $80 \%$ compared with that of control. We further analyzed the susceptibility of transduced cells to 5-FC. The cells were incubated with $5 \mathrm{mg}$ of $\mathrm{yCD}$ fusion proteins in the presence of various concentrations of $5-F C$. The cells transduced with Tat-yCD were susceptible to $5-F C$ in a dose-dependent manner, while the cells transduced with control $y C D$ were not (Figure $3 B$ ). The decreased viability of cells transduced with Tat-yCD suggests that this fusion protein has an antitumor effect on cells in the presence of $5-\mathrm{FC}$.
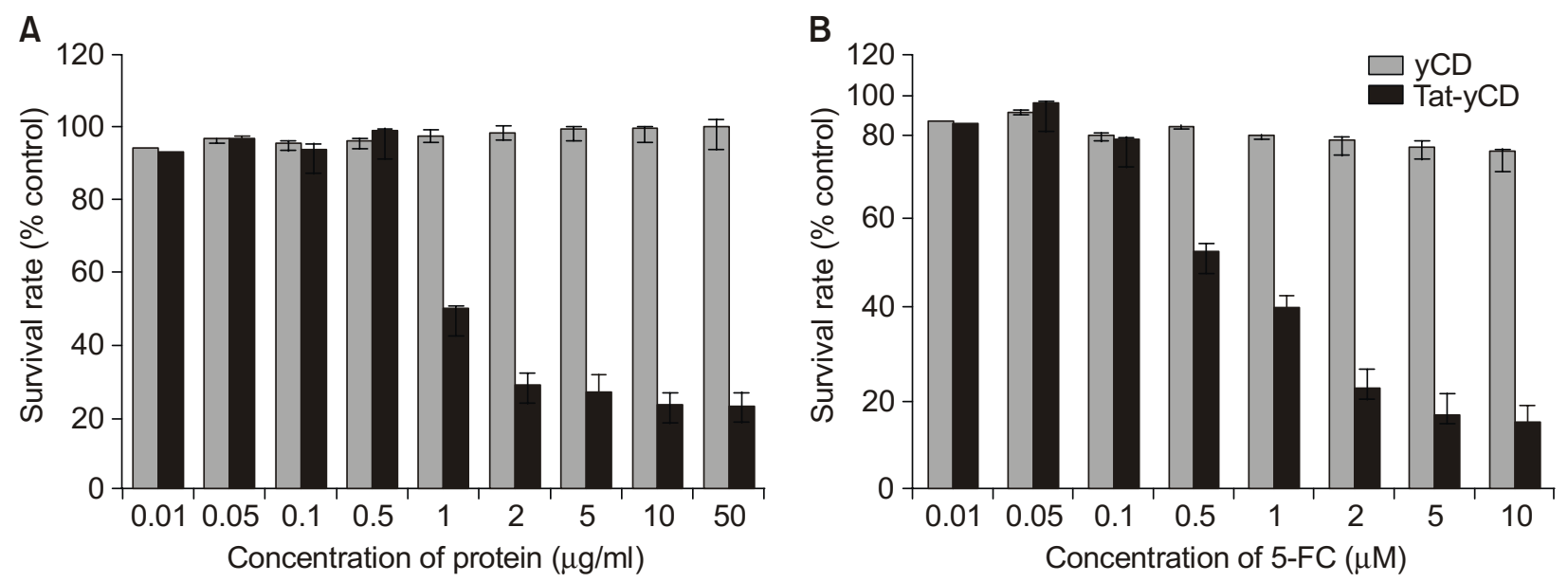

Figure 3. Analysis of cell viability of HeLa cells transduced with Tat-yCD in the presence of 5-FC. (A) HeLa cells were transduced with the various concentrations of $y C D$ fusion proteins in the presence of $10 \mathrm{mM} 5-\mathrm{FC}$ in $0.5 \mathrm{ml}$ medium every $24 \mathrm{~h}$. Percentage of viable cell was measured after $96 \mathrm{~h}$ by MTT. (B) HeLa cells were transduced with $5 \mathrm{mg}$ of the fusion protein in the presence of various concentrations of 5-FC. Percentage of viable cell was measured by MTT. The results are the mean of three separate experiments and are shown with standard deviation. 


\section{Activation of apoptotic pathway in cells transduced with Tat-yCD fusion protein in the presence of $5-\mathrm{FC}$}

To further investigate the cell death in the HeLa cells treated with Tat-yCD and 5-FC, the cellular proteins involved in the apoptotic signaling pathway such as PARP and Bcl-2 were analyzed. Bcl-2 protein regulates the apoptotic cascade and protects cells from apoptosis. The cleavage of PARP and $\mathrm{Bcl}-2$ expression was analyzed in the cells transduced with $\mathrm{YCD}$ or Tat-yCD in the presence of 5-FC (Figure 4). When the cells were treated with control yCD $(1 \mathrm{mM})$ in the

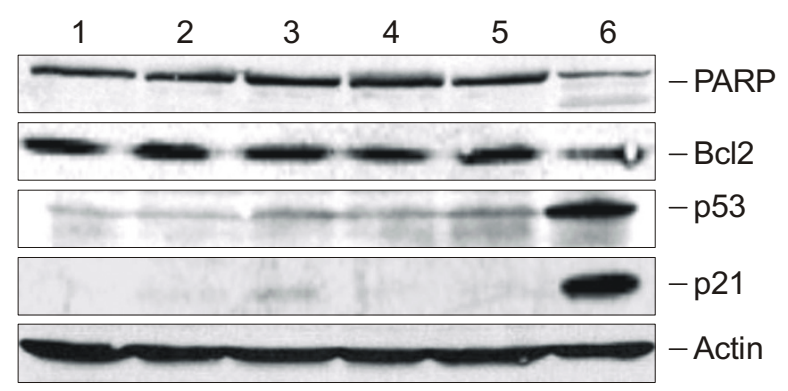

Figure 4. Biochemical analysis of cell death induced by Tat-yCD/5-FC system. HeLa cells were treated with $1 \mathrm{mM}$ of $\mathrm{YCD}$ fusion proteins in the absence or presence of $10 \mathrm{mM}$ of $5-\mathrm{FC}$ for $24 \mathrm{~h}$. Cellular proteins were extracted from the transduced cells, then separated by a SDS-PAGE, and subjected to Western blot analysis with antibodies recognizing p53, p21, PARP, Bcl-2 or actin. The membrane was stripped and reprobed with an indicated antibody. Lane 1, untreated cell; lane 2, yCD; lane 3, Tat-yCD; lane 4, 5-FC; lane 5, yCD and $5-\mathrm{FC}$; lane 6, Tat-yCD and 5-FC. presence of $10 \mathrm{mM} \mathrm{5-FC} \mathrm{for} 24 \mathrm{~h}$, the level of PARP or $\mathrm{Bcl}-2$ protein was not significantly altered (Figure 4, lane 5). However, treatment of cells with Tat-yCD in the presence of $5-\mathrm{FC}$ resulted in the cleavage of PARP and a decrease in the level of $\mathrm{Bcl}-2$ protein (Figure 4, lane 6).

Since p53 and p21 are known to participate in the apoptosis path, the expression of both p53 and p21 during cell death was examined in the prodrug $5-\mathrm{FC}$ activated cells following transduction with Tat-yCD. Western blot analysis showed that treatment of the HeLa cells with control yCD did not change the level of p53 or p21 protein in the cells in the presence of 5-FC (Figure 4, lane 5). However, treatment of the cells with Tat-yCD in combination with $5-F C$ resulted in the induction of p53 as well as p21 protein expression (Figure 4, lane 6). These results suggest that the cell death by prodrug $5-\mathrm{FC}$ activation is partially mediated by the induction of p21 expression in a p53-dependent manner.

\section{Analysis of the bystander effect}

The bystander effect was evaluated by culturing nontransduced cells with the conditioned media from cells transduced with either Tat-yCD or control $y C D$ in the presence of 5-FC. Cells treated with various concentrations of fusion proteins for $2 \mathrm{~h}$ were washed with PBS and incubated in a media containing 5-FC for $24 \mathrm{~h}$. The supernatant from cells transduced with $\mathrm{YCD}$ fusion proteins was added to non-transduced cells and cytotoxic effects on the non-transduced cells were measured with the MTT assay. As shown in
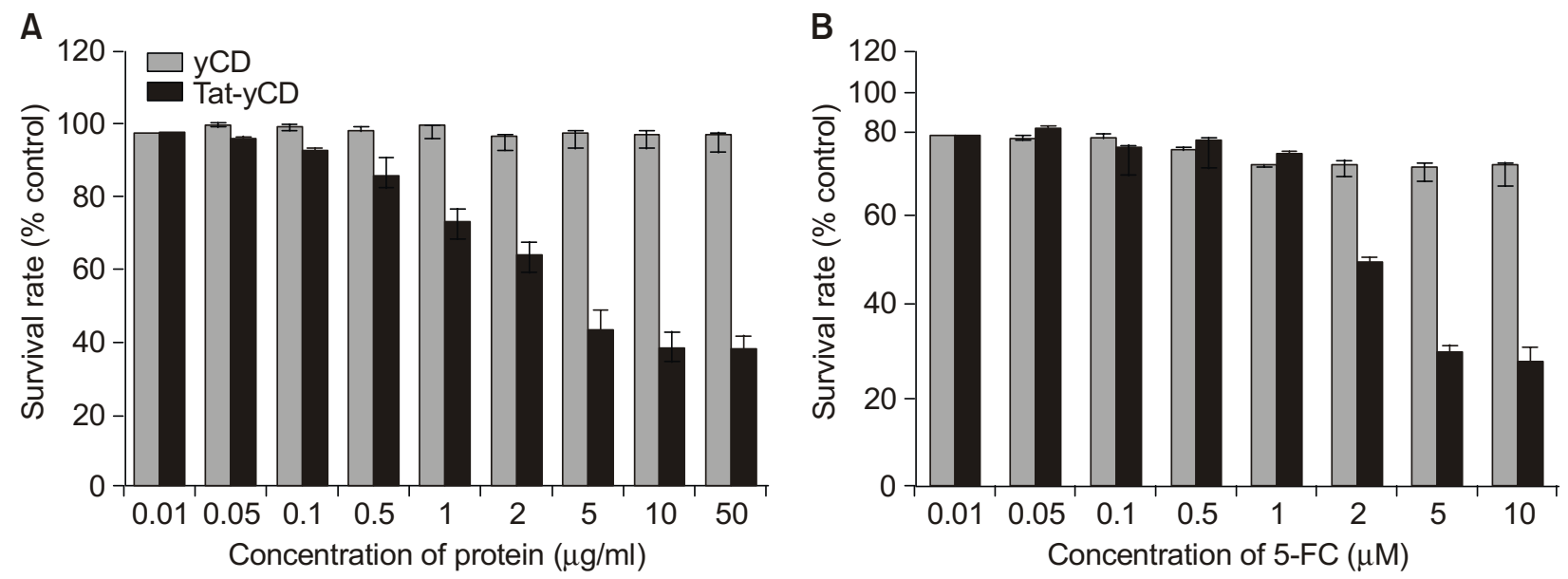

Figure 5. Analysis of the bystander effect. (A) HeLa cells were transduced with the various concentrations of yCD fusion proteins. After $2 \mathrm{~h}$, cells were washed with PBS and incubated in a media containing $10 \mathrm{mM} \mathrm{5-FC} \mathrm{for} 24 \mathrm{~h}$. The supernatant from transduced cells were added to non-transduced HeLa cells every $24 \mathrm{~h}$ for $4 \mathrm{~d}$. Percentage of viable cell was measured by MTT. (B) HeLa cells were transduced with 5 $\mathrm{mg} / \mathrm{ml}$ of the fusion protein for $2 \mathrm{~h}$. Cells were then washed with PBS and incubated in a media containing various concentrations of 5-FC. Culture media were harvested and incubated with fresh HeLa cells every $24 \mathrm{~h}$ for $4 \mathrm{~d}$. Percentage of viable cell was measured by MTT. The results are the mean of three separate experiments and are shown with standard deviation. 
Figure $5 \mathrm{~A}$, viability of the nontrasduced cells was not affected by supernatant from cells transduced with control $y C D$ in the presence of 5-FC. However, the viability of the non-transduced cells cultured with supernatant from cells transduced with Tat-yCD at the various concentrations decreased in a dose-dependent manner, reaching $-60 \%$ at the maximum concentration used. Similar patterns in the viability of the non-trasduced cells were observed when incubated with supernatant from cells transduced with $y C D$ in the presence of $5-\mathrm{FC}$ at the various concentrations (Figure 5B). The decreased viability of cells transduced with Tat-yCD and its bystander effect suggests that Tat-yCD fusion proteins have an antitumor effect on cells in the presence of $5-\mathrm{FC}$.

\section{Discussion}

Various macromoleculs such as enzymes and functional proteins are considered to be a new class of therapeutic agents due to recent progress in protein transduction technology. Prodrug activating system is one of the promising approaches that have been developed to treat cancers. As an approach to improve current enzyme prodrug therapy, yeast cytosine deaminase (yCD) was generated as fusion protein with Tat basic domain which has been shown to efficiently deliver foreign proteins into cells (Schwarze et al., 2000). Tat-yCD fusion protein purified in $E$. coli was efficiently transduced into cells. Cells transduced with Tat-yCD were highly sensitive to $5-F C$ prodrug, indicating efficient conversion of prodrug to drug. In addition, a strong bystander effect was observed when supernatant from cells treated with 5-FC and Tat-yCD was added to non-transduced cells.

Analysis of the transduction profiles of Tat-yCD fusion protein into the cells revealed that the levels of CD in HeLa cells transduced with Tat-yCD were increased in a time- and dose-dependent manner (Figure 2). The intracellular concentration of transduced Tat-yCD into cultured cells was detected after $5 \mathrm{~min}$ and gradually increased by $2 \mathrm{~h}$. This timedependent manner of transduction indicated that Tat-yCD was efficiently transduced into cells. The restoration of enzymatic activities of transduced proteins in the cells is a key point in the enzyme/prodrug therapy for cancers. When deamination activities of $C D$ in the cells treated with Tat-yCD were determined, the enzyme activitiy of $C D$ in HeLa cells transduced with Tat-yCD was increased in a time- and dosedependent manner (data not shown). As shown in Figure 2D, significant levels of enzyme activity were maintained in the HeLa cells transduced with Tat-yCD till $24 \mathrm{~h}$, indicating that the transduced Tat-yCD into cells is able to convert the nontoxic prodrug $5-\mathrm{FC}$ to the toxic metabolite 5-FU.

In vitro studies showed that treatment of cells with 5-FC combined with cell-permeable Tat-yCD resulted in significant cytotoxicity to tumor cells, probably due to the efficient conversion of $5-\mathrm{FC}$ to $5-\mathrm{FU}$ by yeast $C D$ (Figure 3). Transduction of $y C D$ lacking Tat basic domain in cells did not affect the survival rate of these cells. However, introduction of Tat-yCD into cells did increase the sensitivity of these cells to the nontoxic prodrug, 5-FC. The cell viability of HeLa cells treated with $0.25-2 \mathrm{mM}$ Tat-yCD and $10 \mathrm{mM} 5-\mathrm{FC}$ were decreased by approximately $40-80 \%$ compared with that of control. This effect was also observed in both the p53 wild-type (HepG2) and p53 null (PC3) cell lines (data not shown), indicating that the cytotoxic effect exerted by 5-FC/Tat-yCD system on cancer cells is independent of p53 status. Thus, it would be interest to test the benefit of $5-F C / T a t-y C D$ system in combination with chemotherapy or radiation therapy (Hanna et al., 1997; Gabel et al., 1998). In CD/5-FC system, activation of prodrug $5-\mathrm{FC}$ to 5 -FU may result in a bystander effect, since 5 -FU can efflux from the transduced cells and enter into nontransduced cells. Consistent with previous results (Lawrence et al., 1998), when the supernatant of cells transduced with Tat-yCD in the presence of 5-FC was transferred to nontransduced cells, significant cytotoxicity to the nontransduced cells was observed (Figure 5). These results suggest that significant cytotoxicity of 5-FU converted from $5-\mathrm{FC}$ on transduced cells as well as nontransduced cells provide a more efficient antitumor effect on tumor cells. This strong bystander effect will potentiate the therapeutic efficacy of 5-FC/Tat-yCD system. In vivo experiments are going to evaluate the potential antitumor activity. Intratumoral conversion of 5-FC into 5-FU by locally applied cell-permeable TatyCD when combined with systemic administration of 5-FC may induce antitumor activity at a local site without apparent side-effects.

It has been suggested that the apoptosis induced by $5-\mathrm{FC}$ may be a primary mechanism in $\mathrm{CD}$ enzyme/5-FC therapy of cancers (Wang et al., 1998). The apoptotic features of the transduced cells induced by Tat-yCD/5-FC system were confirmed by measuring the level of apoptosis related molecules, such as $\mathrm{Bcl}-2$ expression, and PARP cleavage (Figure 4). In addition, the levels of p53 and p21, which participate in apoptosis, were elevated in the cells treated with Tat-yCD and 5-FC. These data demonstrate that Tat-yCD/5-FC system can induce cell death by apoptosis through these mediators in transduced HeLa cells.

In summary, we demonstrated that in vitro delivery of yeast $C D$ enzyme mediated by Tat basic domain into cells resulted in significant cytotoxic effects on the transduced cells as well as nontransduced cells. 
Therefore, efficient cellular uptake of yeast CD enzyme mediated by Tat basic domain may result in enhanced therapeutic efficacy in treatment of cancers. Further development of the selective targeting of either Tat-yCD or 5-FC will facilitate to develop an effective approach to the treatment of cancer

\section{Acknowledgement}

This work was supported in part by grants from the National Research Laboratory Grant (M1-9911-000025) from the Korean Ministry of Science and Technology, and in part by the Research grant from Hallym University, Korea.

\section{References}

Bradford MM. A rapid and sensitive method for the quantitation of microgram quantities of protein utilizing the principle of protein-dye binding. Anal Biochem 1976;72:248-54

Connors TA. The choice of prodrugs for gene directed enzyme prodrug therapy of cancer. Gene Ther 1995;2:702-9

Deckert PM, Renner C, Cohen LS, Jungbluth A, Ritter G, Bertino JR, Old LJ, Welt S. A33scFv-cytosine deaminase: a recombinant protein construct for antibody-directed enzymeprodrug therapy. $\mathrm{Br} \mathrm{J}$ Cancer 2003;88:937-9

Draus JM, Elliott MJ, Atienza Jr. C, Stilwell A, Wong SL, Dong $\mathrm{Y}$, Yang $\mathrm{H}$ and McMasters KM. p53 gene transfer does not enhance E2F-1-mediated apoptosis in human colon cancer cells. Exp Mol Med 2001;33:209-19

Eum WS, Li MZ, Sin GS, Choi SY, Park JB, Lee JY, Kwon HY. Dexamethasone-induced differentiation of pancreatic AR42J cell involves p21 waf1/cip1 and MAP Kinase pathway. Exp Mol Med 2003;35:379-84

Fawell S, Seery J, Daikh Y, Moore C, Chen LL, Pepinsky $B$, Barsoum J. Tat-mediated delivery of heterologous proteins into cells. Proc Natl Acad Sci USA 1994;91:664-8

Gabel M, Kim JH, Kolozsvary A, Khil M, Freytag S. Selective in vivo radiosensitization by 5 -fluorocytosine of human colorectal carcinoma cells transduced with the $\mathrm{E}$. coli cytosinedeaminase (CD) gene. Int J Radiat Oncol Biol Phys 1998;41: 883-7

Greco O, Dachs GU. Gene directed enzyme/prodrug therapy of cancer: historical appraisal and future prospectives. J Cell Physiol 2001;187:22-36

Hamstra DA, Rice DJ, Fahmy S, Ross BD, Rehemtulla A. Enzyme/prodrug therapy for head and neck cancer using a catalytically superior cytosine deaminase. Hum Gene Ther 1999;10:1993-2003

Hanna NN, Mauceri HJ, Wayne JD, Hallahan DE, Kufe DW, Weichselbaum RR. Virally directed cytosine deaminase/5fluorocytosine gene therapy enhances radiation response in human cancer xenografts. Cancer Res 1997;57:4205-9

Jin LH, Bahn JH, Eum WS, Kwon HY, Jang SH, Han KH, Kang TC, Won MH, Kang JH, Cho SW, Park J, Choi SY.
Transduction of human catalase mediated by an HIV-1 TAT protein basic domain and arginine-rich peptides into mammalian cells. Free Radic Biol Med 2001;31:1509-19

Katsuragi T, Sakai T, Tonomura K. Implantable enzyme capsules for cancer chemotherapy from bakers' yeast cytosine deaminase immobilized on epoxy-acrylic resin and urethane prepolymer. Appl Biochem Biotechnol 1987;16:61-9

Kievit E, Bershad E, Ng E, Sethna P, Dev I, Lawrence TS, Rehemtulla A. Superiority of yeast over bacterial cytosine deaminase for enzyme/prodrug gene therapy in colon cancer xenografts. Cancer Res 1999;59:1417-21

Kievit E, Nyati MK, Ng E, Stegman LD, Parsels J, Ross BD, Rehemtulla A, Lawrence TS. Yeast cytosine deaminase improves radiosensitization and bystander effect by 5 -fluorocytosine of human colorectal cancer xenografts. Cancer Res 2000;60:6649-55

Kuriyama S, Kikukawa M, Masui K, Okuda H, Nakatani T, Sakamoto T, Yoshiji H, Fukui H, Ikenaka K, Mullen CA, Tsujii $T$. Cytosine deaminase/5-fluorocytosine gene therapy can induce efficient anti-tumor effects and protective immunity in immunocompetent mice but not in athymic nude mice. Int J Cancer 1999;81:592-7

Kwon HY, Eum WS, Jang HW, Kang JH, Ryu J, Lee BR, Jin LH, Park J, Choi SY. Transduction of Cu,Zn-superoxide dismutase mediated by a HIV-1 Tat protein basic domain into mammalian cells. FEBS Letter 2000;485:163-7

Lawrence TS, Rehemtulla A, Ng E, Wilson M, Trosko JE, Stetson PL. Preferential cytotoxicity of cells transduced with cytosine deaminase compared to bystander cells after treatment with 5-fluorocytosine. Cancer Res 1998;58:2588-93

Mullen CA, Kilstrup M, Blaese RM. Transfer of the bacterial gene for cytosine deaminase to mammalian cells confers lethal sensitivity to 5 -fluorocytosine: a negative selection system. Proc Natl Acad Sci USA 1992;89:33-7

Nagahara H, Vocero-Akbani AM, Snyder EL, Ho A, Latham DG, Lissy NA, Becker-Hapak M, Ezhevsky SA, Dowdy SF. Transduction of full-length TAT fusion proteins into mammalian cells: TAT-p27Kip1 induces cell migration. Nat Med 1998;4:1449-52

Park JB. Regulation of GTP-binding state in RalA through $\mathrm{Ca}^{+}$and calmodulin. Exp Mol Med 2001;33:54-8

Park J, Ryu J, Kim KA, Lee HJ, Bahn JH, Han K, Choi EY, Lee KS, Kwon HY, Choi SY. Mutational analysis of a human immunodeficiency virus type 1 Tat protein transduction domain which is required for delivery of an exogenous protein into mammalian cells. J Gen Virol 2002;83:1173-81

Sambrook J, Fritsch FE, Maniatis T. Small scale preparations of plasmid DNA. Molecular cloning 1989;1:1.25-1.31

Senter PD, Su PC, Katsuragi T, Sakai T, Cosand WL, Hellstrom I, Hellstrom KE. Generation of 5-fluorouracil from 5fluorocytosine by monoclonal antibody-cytosine deaminase conjugates. Bioconjug Chem 1991;2:447-51

Schwarze SR, Ho A, Vocero-Akbani A, Dowdy SF. In vivo protein transduction: delivery of a biologically active protein into the mouse. Science 1999;285:1569-72

Schwarze SR, Hruska KA, Dowdy SF. Protein transduction: unrestricted delivery into all cells? Trends Cell Biol 2000;10: 
290-5

Song SU, and Boyce FM. Combination treatment for osteosarcoma with baculoviral vector mediated gene therapy (p53) and chemotherapy (adriamycin). Exp Mol Med 2001;33:46-53

Verma IM, Somia N. Gene therapy -- promises, problems and prospects. Nature 1997;389:239-42

Vocero-Akbani AM, Heyden NV, Lissy NA, Ratner L, Dowdy SF. Killing HIV-infected cells by transduction with an HIV protease-activated caspase-3 protein. Nat Med 1999;5:29-33

Wallace PM, MacMaster JF, Smith VF, Kerr DE, Senter PD,
Cosand WL. Intratumoral generation of 5 -fluorouracil mediated by an antibody-cytosine deaminase conjugate in combination with 5-fluorocytosine. Cancer Res 1994;54:2719-23

Wang ZH, Samuels S, Gama Sosa MA, Kolodny EH. 5Fluorocytosine-mediated apoptosis and DNA damage in glioma cells engineered to express cytosine deaminase and their enhancement with interferon. J Neurooncol 1998;36: 219-29

Watson K, Edwards RJ. HIV-1-trans-activating (Tat) protein: both a target and a tool in therapeutic approaches. Biochem Pharmacol 1999;58:1521-8 